\title{
A Systematic Review of the Clinical Efficacy of Treatments in Relapsed or Refractory Diffuse Large B Cell Lymphoma
}

\author{
Per-Olof Thuresson · Nancy Vander Velde $\cdot$ Palvi Gupta • \\ Jonathan Talbot
}

Received: August 19, 2020 / Accepted: September 14, 2020 / Published online: October 1, 2020

(C) The Author(s) 2020

\section{ABSTRACT}

Introduction: Novel treatment options are needed to improve outcomes in transplantineligible relapsed/refractory (R/R) diffuse large B cell lymphoma (DLBCL). This systematic literature review evaluated clinical evidence on treatments for patients with R/R DLBCL ineligible for, or relapsed following, stem cell transplantation.

Methods: We assessed the feasibility of conducting an indirect treatment comparison (ITC) or network meta-analysis (NMA) to evaluate the relative efficacy and safety of polatuzumab vedotin in combination with ben-

Electronic Supplementary Material The online version of this article (https://doi.org/10.1007/s12325020-01507-7) contains supplementary material, which is available to authorized users.

P.-O. Thuresson $(\bowtie) \cdot$ J. Talbot

F. Hoffmann-La Roche Ltd, Basel, Switzerland

e-mail: per-olof.thuresson@roche.com

N. Vander Velde

Tulane University School of Medicine, New Orleans,

LA, USA

P. Gupta

DRG Abacus, Bicester, UK damustine + rituximab versus other relevant treatments.

Results: Thirty-seven studies were identified, of which 20 were eligible [seven randomized, controlled trials (RCTs); 13 observational/single-arm trials]. Due to a lack of RCTs, an ITC/ NMA summary of the relative efficacy and safety of the treatment options was not possible. Only two of the seven RCTs had positive outcomes.

Conclusions: These findings highlight the paucity of published RCTs to establish the comparative efficacy of treatments for transplant-ineligible R/R DLBCL and lack of standard of care in this setting.

Keywords: Diffuse large B cell lymphoma; Polatuzumab vedotin; Systematic literature review 


\section{Key Summary Points}

Why carry out this study?

Outcomes for patients with diffuse large B cell lymphoma (DLBCL) who relapse or are refractory $(\mathrm{R} / \mathrm{R})$ to first-line treatment are poor, especially those who are ineligible for stem cell transplantation (a standard second-line treatment).

The aim of our clinical systematic literature review was to identify clinical evidence on treatment options for these patients and to assess the feasibility of conducting an indirect treatment comparison (ITC) or network metaanalysis (NMA) to evaluate the relative efficacy and safety of polatuzumab vedotin plus bendamustine-rituximab (pola-BR; a recently approved second-line or later treatment) versus other treatments for R/R DLBCL.

\section{What was learned from this study?}

Thirty-seven studies were identified, of which 20 were eligible. Due to a lack of randomized controlled trials (RCTs; seven in total), an ITC/NMA summary of the relative efficacy and safety of the treatment options was not possible, and only two of the seven RCTs had positive outcomes.

These results highlight the lack of published RCTs to establish the comparative efficacy of treatments for transplant-ineligible R/R DLBCL and the lack of standard of care treatment in this setting.

\section{DIGITAL FEATURES}

This article is published with digital features to facilitate understanding of the article. To view digital features for this article go to https://doi. org/10.6084/m9.figshare.12952145.

\section{INTRODUCTION}

Comprising approximately one-third of nonHodgkin lymphoma (NHL), diffuse large B cell lymphoma (DLBCL) is the most common NHL subtype, with an estimated 5.6 per 100,000 men and women diagnosed annually in the US and 6.6 per 100,000 in Europe [1-3]. Standard firstline therapy for DLBCL is rituximab plus cyclophosphamide, doxorubicin, vincristine, and prednisone $[4,5]$. For patients who do not respond to first-line therapy, high-dose chemotherapy followed by autologous stem cell transplantation (SCT) represents a second option for cure $[4,5]$. However, for patients who either relapse after or are not eligible for SCT due to refractory disease or frailty, treatment outcomes are poor [6]. Furthermore, even if some patients are eligible for transplant, very few actually benefit from this treatment [6]. Response rates to subsequent therapies range from $10-35 \%$ in most cases [6-10]; thus, novel treatment options are urgently needed to improve outcomes in transplant-ineligible relapsed/refractory (R/R) DLBCL.

Polatuzumab vedotin (pola) is an antibodydrug conjugate that has been demonstrated to prolong survival in combination with bendamustine + rituximab (BR) compared with BR alone in a phase $1 \mathrm{~b} / 2$ multicenter, open-label study of patients with transplant-ineligible R/R DLBCL (NCT02257567) [11]. Pola, in combination with BR (pola-BR), was approved by the US Food and Drug Administration for third-line or later treatment of R/R DLBCL [12]. The European Commission granted conditional marketing authorization for pola-BR for second-line or later treatment for patients with $\mathrm{R} / \mathrm{R}$ DLBCL who are not candidates for hematopoietic SCT [13], and the Australian health authorities approved pola-BR for second-line or later treatment. These approvals were based on the randomized phase 2 response data from the GO29365 study [11, 14]. A recently published structured review examined the efficacy of treatment beyond frontline therapy for patients 
with transplant-ineligible aggressive B cell NHL (aNHL) [15]. The aim of our clinical systematic literature review (SLR) was to identify current clinical evidence on pharmacologic options for the specific population of patients with $R / R$ DLBCL who were ineligible for, or relapsed following SCT. A secondary objective was to assess the feasibility of conducting an indirect treatment comparison (ITC) or network meta-analysis (NMA) to evaluate the relative efficacy and safety of pola-BR versus other relevant treatments for R/R DLBCL.

\section{METHODS}

This article is based on previously conducted studies and does not contain any studies with human participants or animals performed by any of the authors.

\section{Search Strategy}

Electronic databases (Embase ${ }^{\circledR}$, MEDLINE $^{\circledR}$, and The Cochrane Library) were searched for relevant English-language publications on 10 June 2019 using a predefined search string (see the appendix in the electronic supplementary material). In addition, conference proceedings were screened from January 2015 to June 2019 from the following congresses: European Hematology Association, International Conference on Malignant Lymphoma, American Society of Hematology, American Society of Clinical Oncology, European Society for Medical Oncology, International Society for Pharmacoeconomics and Outcomes Research Annual and European Meetings, Health Technology Assessment International, and Society for Medical Decision Making. Finally, clinical trial registries and health technology assessment submissions were also searched.

\section{Eligibility Criteria}

The eligibility criteria applied were in the form of PICOS (population, intervention, comparators, outcomes and study design). Table S1 in the electronic supplementary material shows the predefined inclusion criteria for the SLR. Briefly, English-language randomized, controlled trials (RCTs) and prospective or comparative observational studies in adults with $\mathrm{R} / \mathrm{R}$ DLBCL receiving licensed or investigational treatments as second- or later-line therapy were included. Pre-clinical/in vitro studies, trials of first-line treatments or non-pharmacologic therapies, reviews/editorials, case reports/case series, and retrospective single-arm studies were excluded.

\section{Study Selection and Data Extraction}

Identified citations were initially reviewed by two independent reviewers to assess eligibility on the basis of title and abstract. Full publications of potentially relevant citations were then obtained and examined in full to identify publications eligible for inclusion in the SLR. Disputes regarding eligibility were resolved through discussion between reviewers. Citations identified by hand searching of reference lists from included publications and also relevant SLRs were also screened. Non-English-language articles with an English abstract were assessed individually for inclusion. Relevant data from included studies were extracted into pre-designed tables in Microsoft ${ }^{\circledR}$ Excel. A quality assessment of included RCTs and observational studies was performed using the Cochrane Collaboration tool and the Downs and Black checklist [16], respectively. The Cochrane tool assesses the risk of bias across categories and studies, and by outcomes [progression-free survival (PFS), complete response (CR)]. The Downs and Black checklist scores studies based on five subscales, including reporting, external validity, bias, confounding and power.

\section{Network-Building Analysis}

Prior to data extraction, a network-building exercise was conducted to identify whether a connected network of evidence could be constructed from the identified studies. Matching Adjusted Indirect Comparisons is a method for comparing single-arm studies, and was used to 


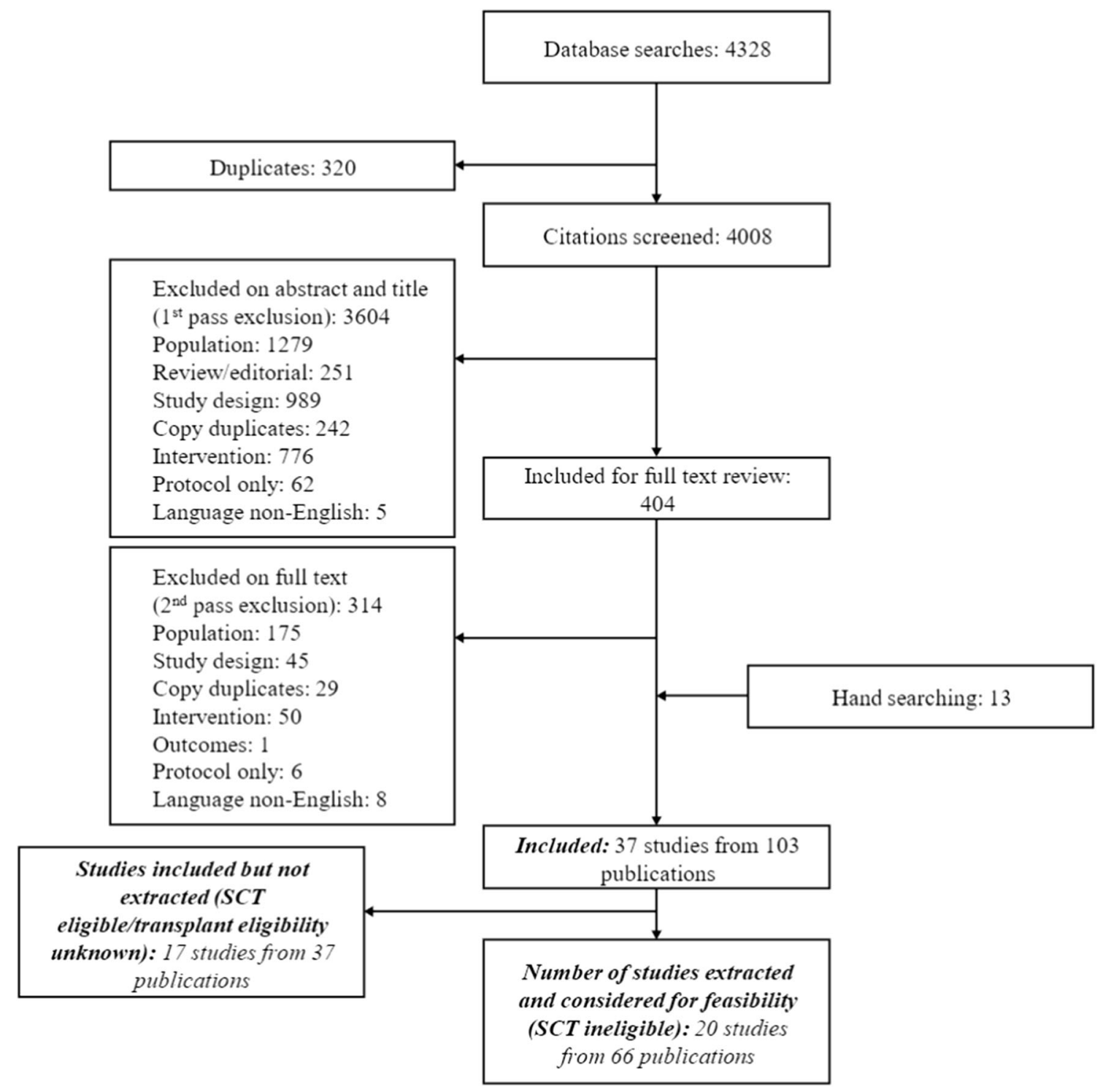

Fig. 1 PRISMA flow diagram of included studies. PRISMA Preferred Reporting Items for Systematic Reviews and MetaAnalyses; SCT stem cell transplant

establish links to interventions not connected to the network through RCTs; these data will be reported separately. A post-hoc supplementary process was then carried out, whereby studies not meeting the SLR protocol criteria were reevaluated to see whether they could be used to help construct a connected network of evidence to provide links between comparators and fill data gaps.

\section{RESULTS}

\section{Search Results}

Overall, the SLR identified 37 studies of patients with R/R DLBCL (103 publications); of these, 20 studies (66 publications) met the eligibility criteria (Fig. 1), including seven RCTs [11, 17-22] and 13 prospective, observational or single-arm trials [9, 23-34]. Table S2 in the electronic supplementary material summarizes the studies 
included in the SLR. The 20 studies included in the review provided data on 13 different interventions (Table 1). The sample size of the included studies varied from 14 patients [31] to 338 patients [20], with 11 studies having a sample size of $<60$ patients $[9,22-26,28,29$, $31,32,34]$. Median follow-up varied from four.Seven [28] to 65.0 months [26]. At the time of literature searching, three studies were published only as a conference abstract $[11,22,30]$. Of the 20 eligible studies, 15 included transplant-ineligible patients and two were considered to be in a transplant-ineligible population because they included elderly frail patients $[17,18]$. Another three studies included transplantation- or chemotherapy-relapsed patients.

An additional three RCTs [36-38] and 14 single-arm studies [39-52] were identified that did not meet the inclusion criteria for the SLR, but were potentially useful for the post-hoc network building exercise (see Fig. S1 in the electronic supplementary materials). The three RCTs did not meet the inclusion criteria for the SLR because they were in SCT-eligible patients $[6,37,38]$.

\section{Baseline Characteristics}

Baseline characteristics in the studies are shown in Table 2. Median patient age across studies ranged from 51-74 years. The proportion of males was well balanced across studies, although five studies had $>65 \%$ male patients $[11,21,27,31,33]$. An imbalance was noted between studies in terms of disease severity, with some studies showing higher proportions of patients with Ann Arbor Stage III-IV disease and a International Prognostic Index score of $3-4[11,18,26]$ than the other studies. Overall, Ann Arbor Stage III-IV disease affected 48-90\% of patients. Among the eight studies that reported individual Ann Arbor disease stages, Stage III disease affected $6-36 \%$ of patients and Stage IV affected $4-87 \%[17,18,20,22$, $27-29,34]$. The number of prior lines of therapy varied from 1 to $\geq 4$ (0-1 line, 3-68\%; 2 lines, 20-44\%; 3 lines, $12-31 \%$; $\geq 4$ lines, $13-35 \%$ ).

\section{Quality Assessment of Included Studies}

Among the seven included RCTs, the studies by Sehn et al. [11] and Pettengell et al. [21] appeared to have the lowest risk for bias. This was based on the results of the quality assessment using the Cochrane critical appraisal tool.

\section{Study Outcomes}

\section{Efficacy Outcomes}

Endpoint definitions varied between studies (see Table S2 in the electronic supplementary materials) limiting potential comparisons. The International Working Group (IWG) 1999-NHL guidelines were the most commonly used criteria to define CR (Fig. 2). Across the included studies, overall response rate (ORR) was the most commonly reported outcome. All 20 studies reported ORR (Table 1; Table S2 in the electronic supplementary materials), with 12 studies measuring ORR as the primary outcome $[9,19,23,24,26-28,30-34]$. The reported ORR for pola-BR was $48 \%$ compared with $18 \%$ in BR group (Table 1) [11]. Similarly, the ORR was higher with pixantrone than with the comparator of the investigator's choice of treatment (37\% vs. $14 \%$; Table 1) [21]. ORR across studies varied between $19 \%$ with lenalidomide [9] and 82\% with axicabtagene ciloceucel (Table 1) [27]. The second most commonly reported outcome was CR (Table 1; table S2 in the electronic supplementary materials). The reported CR rates were $43 \%$ and $15 \%$ for pola-BR vs. BR, respectively (Table 1) [11]. CR rates varied between $12 \%$ with lenalidomide [9] and 73\% with rituximab + gemcitabine + oxaliplatin (R-GemOx; Table 1) [23].

Twelve studies reported median PFS $[11,19-22,25,26,28,31,32]$, which ranged from 2.6-17.1 months (Table 1). One of the most notable results was the longer median PFS with the addition of pola to $\mathrm{BR}$ at a median follow-up of 22.3 months [hazard ratio (HR) 0.34 (95\% confidence interval (CI) 0.2-0.57); Table 1] [11]. Median PFS was higher with pixantrone than with the investigator's choice comparator [HR 0.60 (95\% CI 0.42-0.86), median follow-up 18 months] [21]. Similarly, in the 


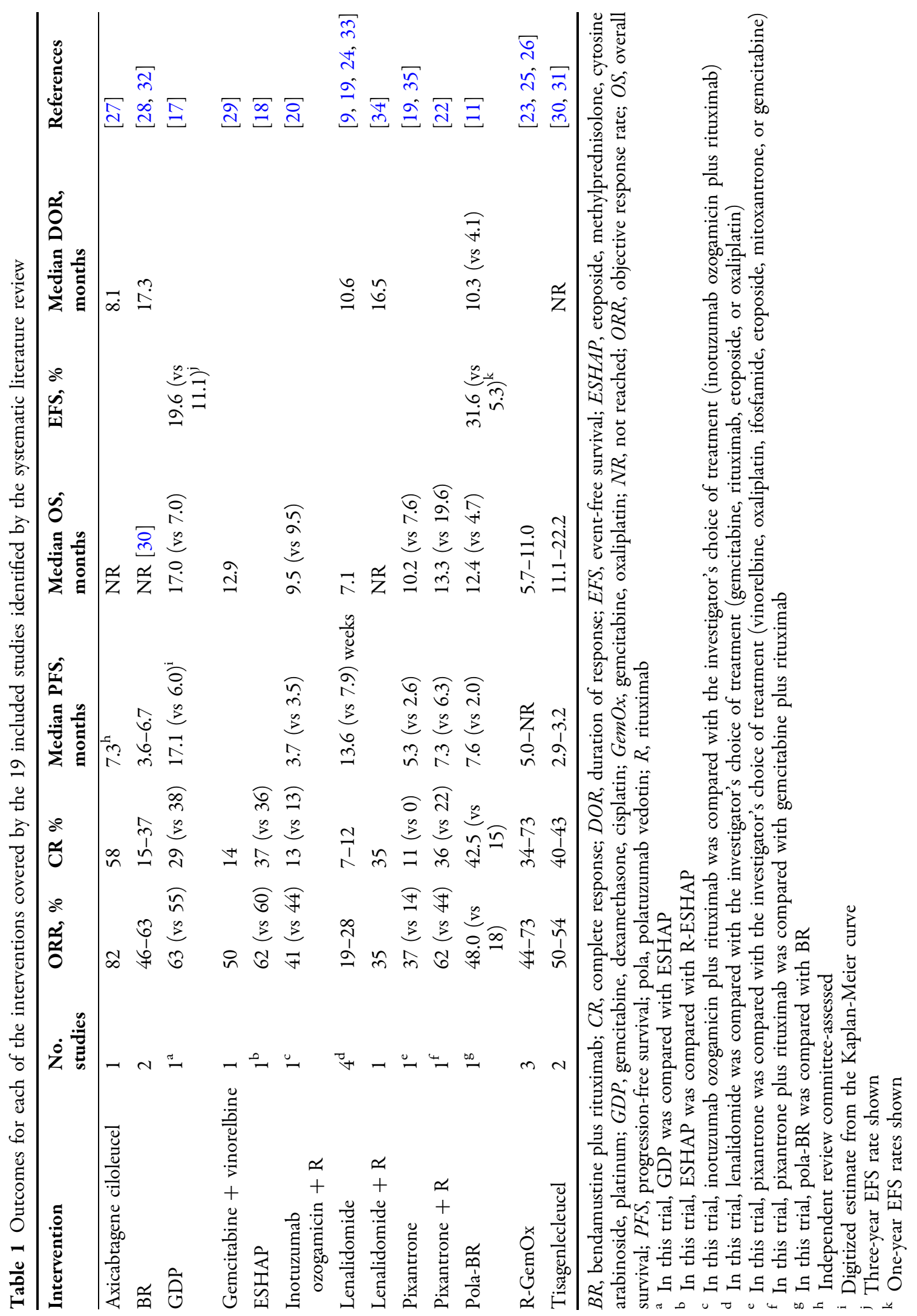




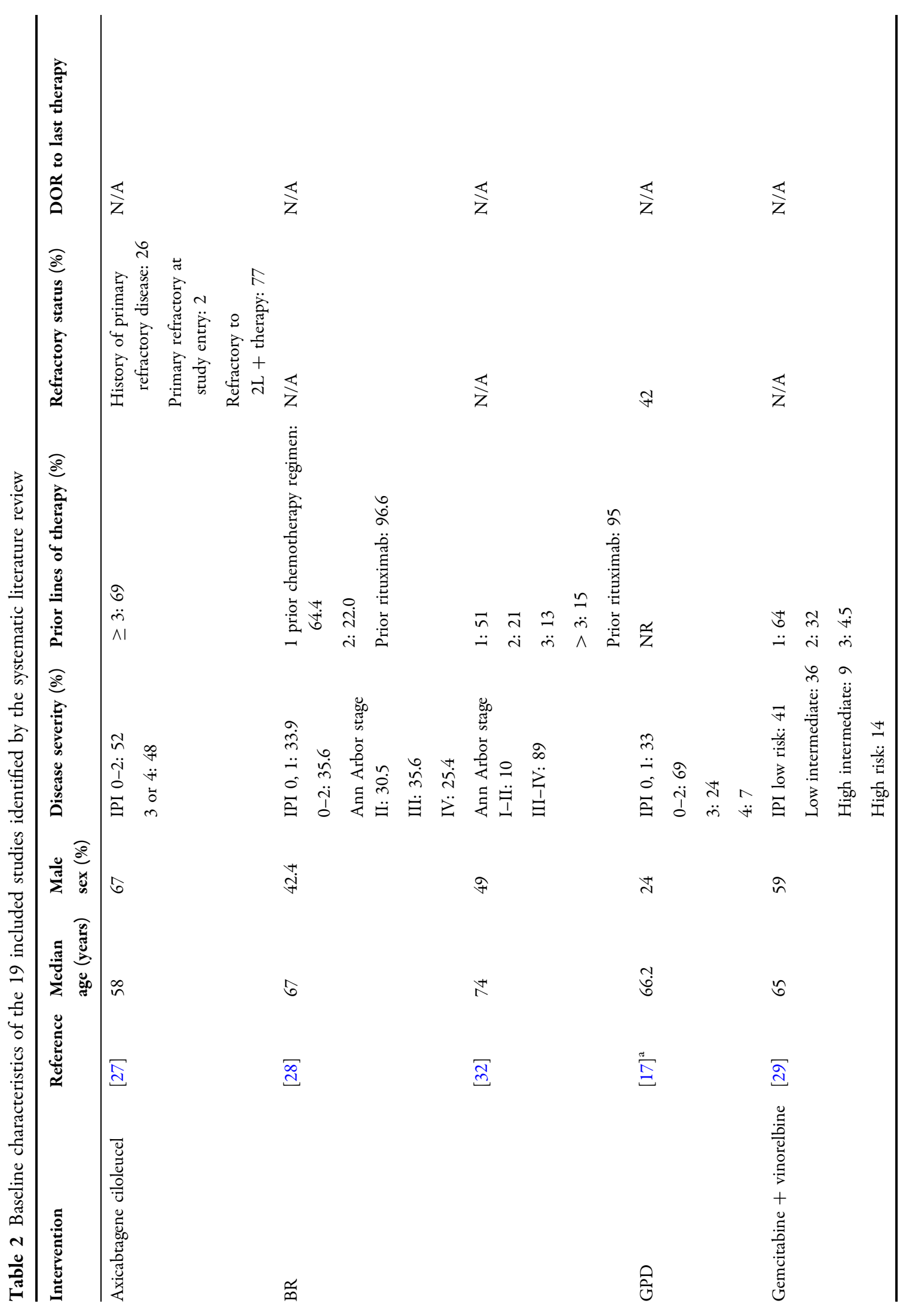




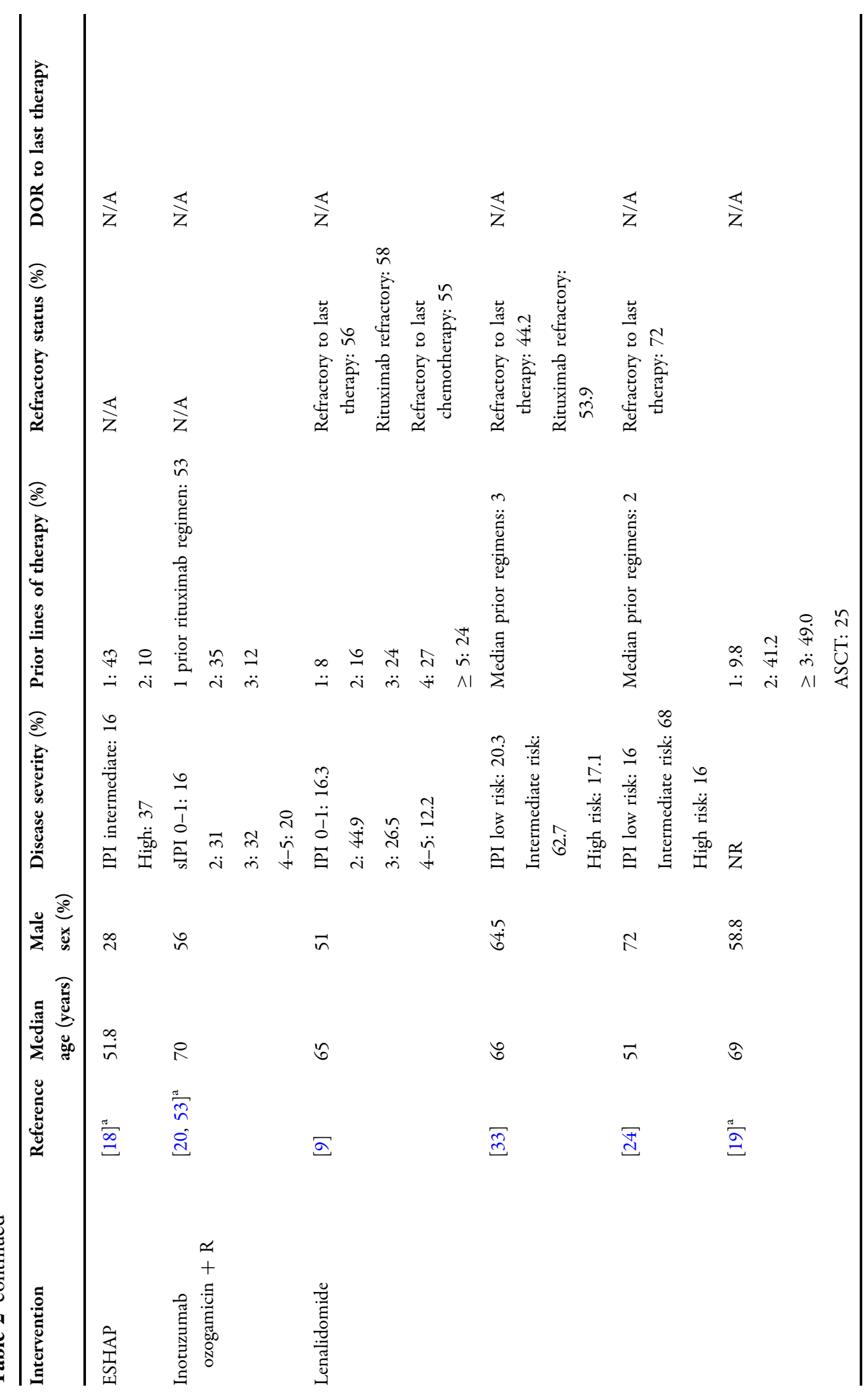




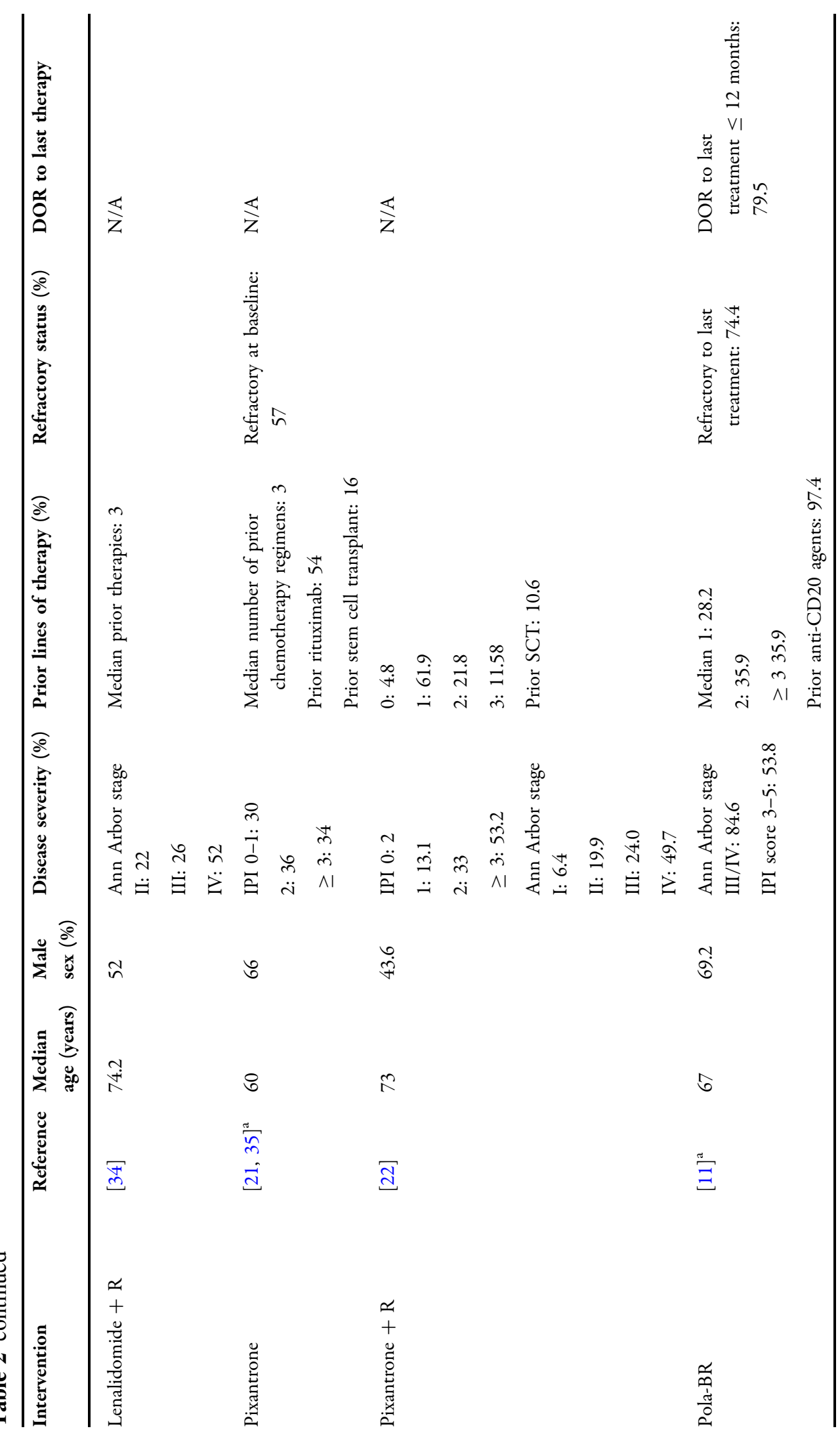




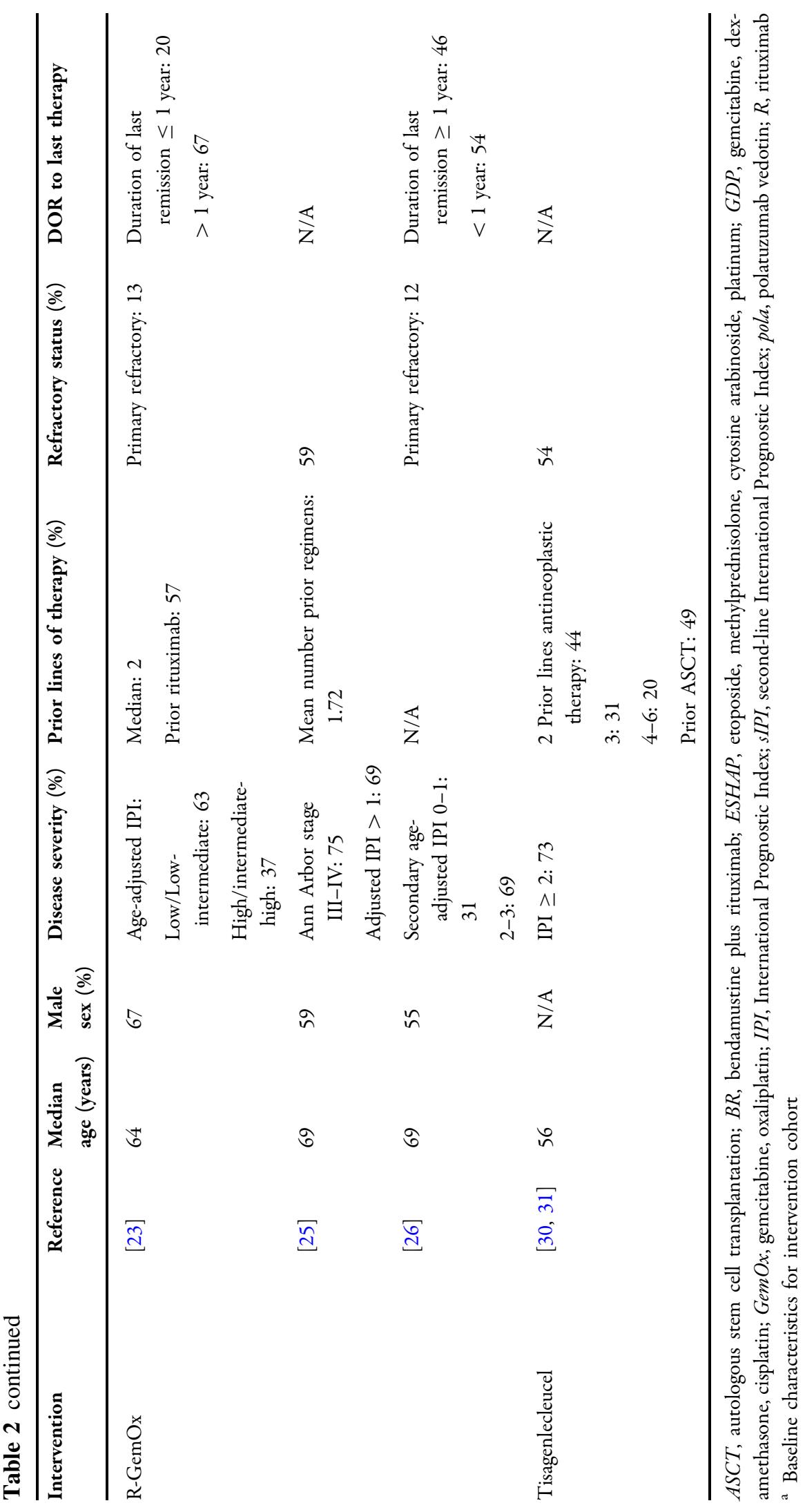




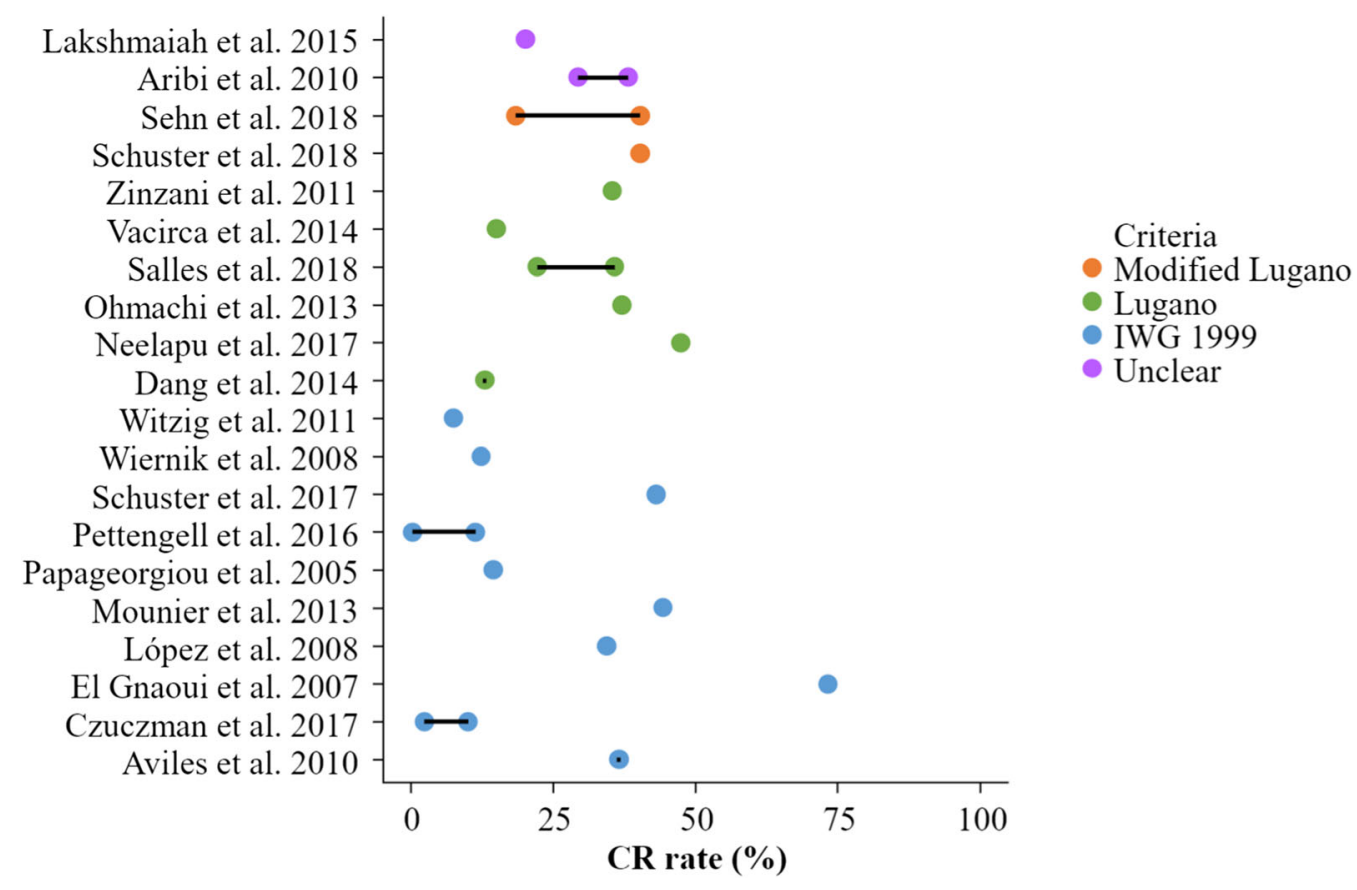

Fig. 2 Assessment criteria used to assess complete response (by investigator) in the included studies. Pettengell et al. 2016 [21] included patients who were rituximab naive and rituximab pretreated ( $54 \%$ of the pixantrone group and

PIX-306 trial median PFS was prolonged with pixantrone + rituximab compared with gemcitabine + rituximab, but the difference was not statistically significant [HR $0.85 \quad(95 \%) \quad$ CI 0.64-1.14), median follow-up 18 months] [22]. Among chimeric antigen receptor T cell (CAR-T) therapies, median PFS was 2.9-3.2 months (median follow-up of 19.0 and 28.6 months, respectively) with tisagenlecleucel $[30,31]$, and 5.8 months (investigator assessed) and 7.3 months (independent review committee) with axicabtagene ciloleucel at a median followup of 15.4 months [27]. In addition, two studies reported 1-year PFS rates $[11,25]$. The PFS rate at 1 year was $46 \%$ with pola-BR (vs. $13 \%$ with BR alone) [11], and 29\% with R-GemOx [25].

Eleven studies reported median overall survival (OS) [11, 19-22, 25, 26, 29-32] with estimates ranging 5.0-22.2 months (Table 1; in two studies, median OS was not reached). An improvement in median OS was observed with the addition of pola to BR [HR 0.42 (95\% CI 0.24-0.75)] [11]. Similarly, median OS for
$56 \%$ of the comparator group received rituximab). $C R$ complete response; $I W G$ International Working Group

pixantrone was higher than the investigator's choice comparator [HR $0.79 \quad(95 \%)$ CI 0.53-1.18)]; however, the difference was not statistically significant [21]. In the PIX-306 trial, median OS was lower with pixantrone + rituximab than with gemcitabine + rituximab [22]. Median OS for R-GemOx ranged from 9.1 [25] to 11.0 months [26], and median OS with tisagenlecleucel ranged from 11.1 [30] to 22.2 months [31]. In addition, three studies reported 1-year OS rates $[11,25,30]$. The OS rate at 1 year was $52 \%$ with pola-BR (vs. $24 \%$ with BR alone) [11], 48\% with tisagenlecleucel [30], and $41 \%$ with R-GemOx [25].

Other reported secondary efficacy outcomes included event-free survival (two studies) $[11,17]$ and duration of response (seven studies) $[11,27,30-34]$ (Table 1; Table S2 in the electronic supplementary materials).

\section{Safety Outcomes}

There was some variation in the safety results presented in the studies; therefore, direct 
comparisons were not feasible. Rates of anycause adverse events (AEs) were similar with pola-BR vs. BR alone (100\% vs. $97.4 \%$ ) [11]. The most common Grade 3/5 AEs that were higher with addition of pola to BR were cytopenias, febrile neutropenia, and infections [11]. Grade $3 / 4$ AEs occurring in $>5 \%$ of patients treated with gemcitabine, dexamethasone, and cisplatin were anemia and leukopenia [17]. Similarly, common Grade 3/4 AEs with R-GemOx were neutropenia (43\%), peripheral neuropathy (7\%), and thrombocytopenia (43\%) [25]. In a single-arm study assessing the efficacy and safety of tisagenlecleucel, $86 \%$ of patients had Grade 3/4 AEs [30]. Furthermore, with axicabtagene ciloleucel, $67 \%$ and $27 \%$ of patients had Grade 3/4 neutropenia and febrile neutropenia, respectively [27]. Among the CAR-T therapies, rates of cytokine release syndrome and neurologic events (any grade) were lower with tisagenlecleucel than with axicabtagene ciloleucel ( $57 \%$ vs. $93 \%$, and $20 \%$ vs. $64 \%$, respectively) $[27,30]$. Two patients treated with axicabtagene ciloleucel died because of AEs [27]; no treatment-related deaths were reported with tisagenlecleucel [30].

\section{Network-Building Analysis}

It was not possible to construct a connected network of evidence using data from either RCTs or the broader post-hoc study inclusion (Fig. S1 in the electronic supplementary materials). Because of this, conducting an NMA was deemed unfeasible.

\section{DISCUSSION}

This SLR provides a summary of currently published evidence regarding treatments for $R / R$ DLBCL. The findings from the review highlight that there is a paucity of published RCTs comparing alternative treatments for DLBCL, which is understandable since some of these therapies (e.g., pola, CAR-T therapies) have only been available for approximately 2 years. Only 10/37 studies $(27 \%)$ were RCTs, including three that did not meet the inclusion criteria of transplant ineligibility, preventing implementation of an
ITC or NMA. Furthermore, it was difficult to summarize the relative efficacy and safety of the different treatment options due to a lack of robust published evidence. Only two of the seven RCTs that met the inclusion criteria had positive outcomes (i.e. the intervention under study was more effective than the comparator in terms of response) $[11,21]$; of those, one was in the second-line and beyond setting and one was in the third-line and beyond setting.

A limitation to the comparison of the interventions assessed in this review was the differences in the baseline characteristics of enrolled patients (Table 2). There were large differences in terms of median age, which ranged from 51 to 74 years $[24,34]$, and the proportion of male patients, ranging from 24 to $72 \%$ [17, 24]. There were also differences in terms of prior therapies patients received, and only five studies reported the proportion of patients who received prior rituximab treatment (Table 2), which ranged from 53 to $97 \%$ for inotuzumab ozogamicin and $\mathrm{BR}$, respectively $[20,28]$. The large variation in the refractory status of patients between studies also makes comparison of the interventions difficult due to the poor prognosis associated with refractory patients. Another limitation was the difference in grading criteria of cytokine release syndrome between the CAR-T trials. The axicabtagene ciloleucel trials used the Lee et al. (2014) criteria [54], whereas the tisagenleucel trials used the University of Pennsylvania (Penn) grading scale [55]. Due to differences in these two methods, the Penn criteria usually assign a higher grade of cytokine release syndrome compared with the Lee criteria, which impacts the comparability of safety data between different CAR-T trials [56].

The findings from this review are consistent with those of a recently published structured review, which concluded that the efficacy of current treatments is modest and there is an unmet need for novel, effective, and tolerable treatments for patients with R/R aNHL who are ineligible for or have failed SCT [15]. However, the review by Salles et al. [15] had slightly different eligibility criteria than the current review, for example, the review focused on patients with aNHL, while the current review focused on one subtype i.e., DLBCL. 
Furthermore, incorporation of three identified RCTs in transplant-eligible patients into the post-hoc network-building exercise in the current review allowed consideration of a broader population than in the earlier review, which focused on transplant-ineligible or failed SCT patients only [15]. The findings from this review are also consistent with a recently published real-world study by Ionescu-Ittu and colleagues [57], which analyzed second-line therapies for $\mathrm{R} / \mathrm{R}$ DLBCL used in US clinical practice. The results showed heterogeneity, with 200 distinct therapy regimens used in 702 included patients [57], highlighting the unmet need in this treatment landscape.

Imaging assessment criteria have become more stringent over time [58-60]. Despite this, the recent study of pola-BR achieved among the highest $\mathrm{CR}$ in $\mathrm{R} / \mathrm{R}$ DLBCL using the strictest response criteria [11]. Responses were assessed by CT, PET-CT, and bone marrow examination (if required to confirm $\mathrm{CR}$ ) as per study protocol.

A strength of the current study is its systematic approach to literature searching. Despite this, the lack of published studies hampered any clinically meaningful analysis of outcomes. In addition, the differences in patient baseline characteristics and reported efficacy and safety outcomes made it difficult to compare results between the different interventions in the trials. Therefore, we recommend that an indirect comparison should be conducted to account for the differences in the trials in the DLBCL setting.

\section{CONCLUSIONS}

These findings highlight the paucity of published RCTs to establish the comparative efficacy of treatments for R/R DLBCL, and demonstrate a fragmented treatment landscape and lack of standard of care in this setting.

\section{ACKNOWLEDGEMENTS}

We thank Naseer Qayum for his contributions to the analysis.
Funding. This work was funded by F. Hoffmann-La Roche Ltd, who also funded the journal's Rapid Service and Open Access Fees.

Medical Writing Assistance. Third-party medical writing assistance was provided by Rachel Hubbard, of Gardiner-Caldwell Communications, and was funded by F. HoffmannLa Roche Ltd.

Authorship. All named authors meet the International Committee of Medical Journal Editors (ICMJE) criteria for authorship for this article, take responsibility for the integrity of the work as a whole, and have given their approval for this version to be published.

Disclosures. Per-Olof Thuresson and Jonathan Talbot are employees of and have ownership interests in F. Hoffmann La-Roche Ltd. Nancy Vander Velde is an employee of Tulane University and Southeast Louisiana Veterans Affairs Health Care System. Palvi Gupta is an employee of Decisions Resource Group, Part of Clarivate.

Compliance with Ethics Guidelines. This article is based on previously conducted studies and does not contain any studies with human participants or animals performed by any of the authors.

Data Availability. Qualified researchers may request access to individual patient level data through the clinical study data request platform (https://vivli.org/). Further details on Roche's criteria for eligible studies are available here (https://vivli.org/members/ourmembers/). For further details on Roche's Global Policy on the Sharing of Clinical Information and how to request access to related clinical study documents, see here (https://www.roche.com/ research_and_development/who_we_are_how_ we_work/clinical_trials/our_commitment_to_ data_sharing.htm).

Open Access. This article is licensed under a Creative Commons Attribution-NonCommercial 4.0 International License, which permits any non-commercial use, sharing, adaptation, 
distribution and reproduction in any medium or format, as long as you give appropriate credit to the original author(s) and the source, provide a link to the Creative Commons licence, and indicate if changes were made. The images or other third party material in this article are included in the article's Creative Commons licence, unless indicated otherwise in a credit line to the material. If material is not included in the article's Creative Commons licence and your intended use is not permitted by statutory regulation or exceeds the permitted use, you will need to obtain permission directly from the copyright holder. To view a copy of this licence, visit http://creativecommons.org/licenses/bync/4.0/.

\section{REFERENCES}

1. Al-Hamadani M, Habermann TM, Cerhan JR, et al. Non-Hodgkin lymphoma subtype distribution, geodemographic patterns, and survival in the US: a longitudinal analysis of the National Cancer Data Base from 1998 to 2011. Am J Hematol. 2015;90(9): 790-5. https://doi.org/10.1002/ajh.24086.

2. SEER. Cancer stat facts: NHL-diffuse large B cell lymphoma (DLBCL). In: Institute NC, editor. 2019. https://seer.cancer.gov/statfacts/html/nhl.html. Accessed June 2020.

3. Smith A, Crouch S, Lax S, et al. Lymphoma incidence, survival and prevalence 2004-2014: sub-type analyses from the UK's Haematological Malignancy Research Network. Br J Cancer. 2015;112(9): 1575-84. https://doi.org/10.1038/bjc.2015.94.

4. National Comprehensive Cancer Network. NCCN Clinical Practice Guidelines in Oncology (NCCN Guidelines $\left.{ }^{\circledR}\right)$ : B Cell Lymphomas, Version 4.2019. 2019.

5. Tilly H, Gomes da Silva M, Vitolo U, et al. Diffuse large B-cell lymphoma (DLBCL): ESMO clinical practice guidelines for diagnosis, treatment and follow-up. Ann Oncol. 2015;26(Suppl 5):116-25. https://doi.org/10.1093/annonc/mdv304.

6. Crump M, Neelapu SS, Faroog U, et al. Outcomes in refractory diffuse large B-cell lymphoma: results from the international SCHOLAR-1 study. Blood. 2017;130(16):1800-8. blood-2017-03-769620.
7. Coleman M, Martin P, Ruan J, et al. Prednisone, etoposide, procarbazine, and cyclophosphamide (PEP-C) oral combination chemotherapy regimen for recurring/refractory lymphoma: low-dose metronomic, multidrug therapy. Cancer. 2008;112(10):2228-32. https://doi.org/10.1002/ cncr.23422.

8. Robertson MJ, Kahl BS, Vose JM, et al. Phase II study of enzastaurin, a protein kinase $\mathrm{C}$ beta inhibitor, in patients with relapsed or refractory diffuse large B cell lymphoma. J Clin Oncol. 2007;25(13):1741-6. https://doi.org/10.1200/JCO.2006.09.3146.

9. Wiernik PH, Lossos IS, Tuscano JM, et al. Lenalidomide monotherapy in relapsed or refractory aggressive non-Hodgkin's lymphoma. J Clin Oncol. 2008;26(30):4952-7. https://doi.org/10. 1200/JCO.2007.15.3429.

10. Wang L, Lam H, Shou Y, et al. Meta-analytical methods for estimating outcomes from overall response rate in patients with relapsed/refractory diffuse large B cell lymphoma. Oncotarget. 2019;10(35):3285-93. https://doi.org/10.18632/ oncotarget. 26904.

11. Sehn LH, Herrera AF, Matasar MJ, et al. Polatuzumab vedotin (pola) plus bendamustine (B) with rituximab $(\mathrm{R})$ or obinutuzumab $(\mathrm{G})$ in relapsed/refractory (R/R) diffuse large $B$ cell lymphoma (DLBCL): updated results of a phase (Ph) Ib/II study. Blood. 2018;132(Suppl 1):1683. https://doi.org/10. 1182/blood-2018-99-118551.

12. Polivy USPI. 2019. https://www.accessdata.fda.gov/ drugsatfda_docs/label/2019/761121s000lbl.pdf. Accessed June 2020.

13. SCT: Polivy SmPC. 2020. https://www.ema.europa. eu/en/documents/product-information/polivyepar-product-information_en.pdf. Accessed June 2020.

14. Genentech Inc. POLIVY ${ }^{\mathrm{TM}}$ (polatuzumab vedotinpiiq) for injection, for intravenous use. 2019. https://www.accessdata.fda.gov/drugsatfda_docs/ label/2019/761121s000lbl.pdf. Accessed June 2020.

15. Salles GA, Pettengell R, Cordoba R, et al. Treatment of aggressive $\mathrm{B}$ cell non-Hodgkin lymphoma beyond frontline therapy in patients not eligible for stem cell transplantation: a structured review. Leuk Lymphoma. 2019;60(7):1610-25. https://doi.org/ 10.1080/10428194.2018.1564828.

16. Downs SH, Black N. The feasibility of creating a checklist for the assessment of the methodological quality both of randomised and non-randomised studies of health care interventions. J Epidemiol Community Health. 1998;52(6):377-84. https:// doi.org/10.1136/jech.52.6.377. 
17. Aribi M, Mesli N, Remla N, et al. Gemcitabine and treatment of diffuse large $\mathrm{B}$ cell lymphoma in relapsed or refractory elderly patients: a prospective randomized trial in Algeria. J Cancer Res Ther. 2010;6(1):41-6. https://doi.org/10.4103/0973-1482. 63572.

18. Aviles A, Neri N, Huerta-Guzman J, et al. ESHAP versus rituximab-ESHAP in frail patients with refractory diffuse large $B$ cell lymphoma. Clin Lymphoma Myeloma Leuk. 2010;10(2):125-8. https://doi.org/10.3816/CLML.2010.n.017.

19. Czuczman MS, Trneny M, Davies A, et al. A Phase 2/3 multicenter, randomized, open-label study to compare the efficacy and safety of lenalidomide versus investigator's choice in patients with relapsed or refractory diffuse large B Cell lymphoma. Clin Cancer Res. 2017;23(15):4127-37. https://doi.org/10.1158/1078-0432.CCR-16-2818.

20. Dang NH, Ogura M, Castaigne S, et al. Randomized, phase 3 trial of inotuzumab ozogamicin plus rituximab (R-InO) versus chemotherapy for relapsed/refractory aggressive B-cell non-Hodgkin lymphoma (B-NHL). J Clin Oncol. 2014;32(15_ Suppl):8529. https://doi.org/10.1200/jco.2014.32. 15_suppl.8529.

21. Pettengell R, Sebban C, Zinzani PL, et al. Monotherapy with pixantrone in histologically confirmed relapsed or refractory aggressive B cell non-Hodgkin lymphoma: post-hoc analyses from a phase III trial. Br J Haematol. 2016;174(5):692-9. https://doi.org/10.1111/bjh.14101.

22. Salles GA, Jurczak W, Andorsky DJ, et al. Results of a Phase 3 randomised multicenter study comparing pixantrone + rituximab with gemcitabine + rituximab in patients with relapsed aggressive B-cell non-Hodgkin lymphoma not eligible for stem cell transplantation. Blood. 2018;132(Suppl 1):4189. https://doi.org/10.1182/blood-2018-99-112455.

23. El Gnaoui T, Dupuis J, Belhadj K, et al. Rituximab, gemcitabine and oxaliplatin: an effective salvage regimen for patients with relapsed or refractory B-cell lymphoma not candidates for high-dose therapy. Ann Oncol. 2007;18(8):1363-8. https:// doi.org/10.1093/annonc/mdm133.

24. Lakshmaiah KC, Rachan Shetty KS, Sathyanarayanan $\mathrm{V}$, et al. Lenalidomide in relapsed refractory non-Hodgkin's lymphoma: an Indian perspective. J Cancer Res Ther. 2015;11(4):857-61. https://doi.org/10.4103/0973-1482.151418.

25. Lopez A, Gutierrez A, Palacios A, et al. GEMOX-R regimen is a highly effective salvage regimen in patients with refractory/relapsing diffuse large-cell lymphoma: a phase II study. Eur J Haematol.
2008;80(2):127-32. https://doi.org/10.1111/j.16000609.2007.00996.x.

26. Mounier N, El Gnaoui T, Tilly H, et al. Rituximab plus gemcitabine and oxaliplatin in patients with refractory/relapsed diffuse large B-cell lymphoma who are not candidates for high-dose therapy. A phase II Lymphoma Study Association trial. Haematologica. 2013;98(11):1726-31. https://doi.org/ 10.3324/haematol.2013.090597.

27. Neelapu SS, Locke FL, Bartlett NL, et al. Axicabtagene ciloleucel CAR T-cell therapy in refractory large B-Cell lymphoma. $\mathrm{N}$ Engl J Med. 2017;377(26):2531-44. https://doi.org/10.1056/ NEJMoa1707447.

28. Ohmachi K, Niitsu N, Uchida T, et al. Multicenter phase II study of bendamustine plus rituximab in patients with relapsed or refractory diffuse large B-cell lymphoma. J Clin Oncol. 2013;31(17): 2103-9. https://doi.org/10.1200/JCO.2012.46.5203.

29. Papageorgiou ES, Tsirigotis P, Dimopoulos M, et al. Combination chemotherapy with gemcitabine and vinorelbine in the treatment of relapsed or refractory diffuse large B-cell lymphoma: a phase-II trial by the Hellenic Cooperative Oncology Group. Eur J Haematol. 2005;75(2):124-9. https://doi.org/10. 1111/j.1600-0609.2005.00482.x.

30. Schuster SJ, Bishop MR, Tam C, et al. Sustained disease control for adult patients with relapsed or refractory diffuse large B-Cell lymphoma: an updated analysis of juliet, a global pivotal phase 2 trial of tisagenlecleucel. Blood. 2018;132(Suppl 1):1684. https://doi.org/10.1182/blood-2018-99-115252.

31. Schuster SJ, Svoboda J, Chong EA, et al. Chimeric antigen receptor $\mathrm{T}$ cells in refractory B-cell lymphomas. N Engl J Med. 2017;377(26):2545-54. https://doi.org/10.1056/NEJMoa1708566.

32. Vacirca JL, Acs PI, Tabbara IA, et al. Bendamustine combined with rituximab for patients with relapsed or refractory diffuse large B cell lymphoma. Ann Hematol. 2014;93(3):403-9. https://doi.org/10. 1007/s00277-013-1879-x.

33. Witzig TE, Vose JM, Zinzani PL, et al. An international phase II trial of single-agent lenalidomide for relapsed or refractory aggressive B-cell non-Hodgkin's lymphoma. Ann Oncol. 2011;22(7):1622-7. https://doi.org/10.1093/annonc/mdq626.

34. Zinzani PL, Pellegrini C, Gandolfi L, et al. Combination of lenalidomide and rituximab in elderly patients with relapsed or refractory diffuse large B-cell lymphoma: a phase 2 trial. Clin Lymphoma Myeloma Leuk. 2011;11(6):462-6. https://doi.org/ 10.1016/j.clml.2011.02.001. 
35. Pettengell R, Coiffier B, Narayanan G, et al. Pixantrone dimaleate versus other chemotherapeutic agents as a single-agent salvage treatment in patients with relapsed or refractory aggressive nonHodgkin lymphoma: a phase 3, multicentre, openlabel, randomised trial. Lancet Oncol. 2012;13(7): 696-706. 2045(12)70212-7.

36. Crump M, Kuruvilla J, Couban S, et al. Randomized comparison of gemcitabine, dexamethasone, and cisplatin versus dexamethasone, cytarabine, and cisplatin chemotherapy before autologous stem-cell transplantation for relapsed and refractory aggressive lymphomas: NCIC-CTG LY.12. J Clin Oncol. 2014;32(31):3490-6. https://doi.org/10.1200/JCO. 2013.53.9593.

37. Fayad L, Ansell SM, Advani R, et al. Dacetuzumab plus rituximab, ifosfamide, carboplatin and etoposide as salvage therapy for patients with diffuse large B-cell lymphoma relapsing after rituximab, cyclophosphamide, doxorubicin, vincristine and prednisolone: a randomized, double-blind, placebocontrolled phase $2 \mathrm{~b}$ trial. Leuk Lymphoma. 2015;56(9):2569-78. https://doi.org/10.3109/ 10428194.2015.1007504.

38. Gisselbrecht C, Glass B, Mounier N, et al. Salvage regimens with autologous transplantation for relapsed large B-cell lymphoma in the rituximab era. J Clin Oncol. 2010;28(27):4184-90. https://doi. org/10.1200/JCO.2010.28.1618.

39. Bartlett NL, Smith MR, Siddiqi T, et al. Brentuximab vedotin activity in diffuse large B-cell lymphoma with CD30 undetectable by visual assessment of conventional immunohistochemistry. Leuk Lymphoma. 2017;58(7):1607-16. https://doi.org/10. 1080/10428194.2016.1256481.

40. Davids MS, Roberts AW, Seymour JF, et al. Phase I first-in-human study of venetoclax in patients with relapsed or refractory non-hodgkin lymphoma. J Clin Oncol. 2017;35(8):826-33. https://doi.org/ 10.1200/JCO.2016.70.4320.

41. Gumenyuk S, Marchesi F, Borza PA, et al. Salvage treatment with R-IEV (rituximab, ifosfamide, epirubicin, etoposide) and autologous stem cell transplant for relapsed/refractory diffuse large B-cell lymphoma. Haematologica. 2016. https://doi.org/ 10.1080/10428190802094229.

42. Hertzberg MS, Crombie C, Benson W, et al. Outpatient-based ifosfamide, carboplatin and etoposide (ICE) chemotherapy in transplant-eligible patients with non-Hodgkin's lymphoma and Hodgkin's disease. Ann Oncol. 2003;14(Suppl 1):i11-i16. https://doi.org/10.1093/annonc/mdg703.
43. Jacobsen ED, Sharman JP, Oki Y, et al. Brentuximab vedotin demonstrates objective responses in a phase 2 study of relapsed/refractory DLBCL with variable CD30 expression. Blood. 2015;125(9): 1394-402. https://doi.org/10.1182/blood-2014-09598763.

44. Jerkeman M, Leppa S, Kvaloy S, et al. ICE (ifosfamide, carboplatin, etoposide) as second-line chemotherapy in relapsed or primary progressive aggressive lymphoma-the Nordic Lymphoma Group experience. Eur J Haematol. 2004;73(3): 179-82. https://doi.org/10.1111/j.1600-0609.2004. 00294.x.

45. Jermann M, Jost LM, Taverna $C$, et al. Rituximab$\mathrm{EPOCH}$, an effective salvage therapy for relapsed, refractory or transformed B-cell lymphomas: results of a phase II study. Ann Oncol. 2004;15(3):511-6. https://doi.org/10.1093/annonc/mdh093.

46. Jurczak W, Zinzani PL, Gaidano G, et al. Phase IIa study of the CD19 antibody MOR208 in patients with relapsed or refractory B-cell non-Hodgkin's lymphoma. Ann Oncol. 2018;29(5):1266-72. https://doi.org/10.1093/annonc/mdy056.

47. Martin A, Conde E, Arnan M, et al. R-ESHAP as salvage therapy for patients with relapsed or refractory diffuse large B-cell lymphoma: the influence of prior exposure to rituximab on outcome. A GEL/TAMO study. Haematologica. 2008;93(12): 1829-36. https://doi.org/10.3324/haematol.13440.

48. Proctor SJ, Taylor PR, Angus B, et al. High-dose ifosfamide in combination with etoposide and epirubicin (IVE) in the treatment of relapsed/refractory Hodgkin's disease and non-Hodgkin's lymphoma: a report on toxicity and efficacy. Eur J Haematol Suppl. 2001;64:28-322.

49. Tobinai K, Igarashi $\mathrm{T}$, Itoh $\mathrm{K}$, et al. Japanese multicenter phase II and pharmacokinetic study of rituximab in relapsed or refractory patients with aggressive B-cell lymphoma. Ann Oncol. 2004;15(5):821-30. https://doi.org/10.1093/ annonc/mdh176.

50. Wang M, Fowler N, Wagner-Bartak N, et al. Oral lenalidomide with rituximab in relapsed or refractory diffuse large cell, follicular and transformed lymphoma: a phase II clinical trial. Leukemia. 2013;27(9):1902-9. https://doi.org/10.1038/leu. 2013.95 .

51. Wilder DD, Ogden JL, Jain VK. A multicenter trial of infusional etoposide, doxorubicin, and vincristine with cyclophosphamide and prednisone $(\mathrm{EPOCH})$ in patients with relapsed non-Hodgkin's lymphoma. Clin Lymphoma. 2001;1(4):285-92. https://doi.org/10.3816/clm.2001.n.003. 
52. Zelenetz AD, Hamlin P, Kewalramani T, et al. Ifosfamide, carboplatin, etoposide (ICE)-based secondline chemotherapy for the management of relapsed and refractory aggressive non-Hodgkin's lymphoma. Ann Oncol. 2003;14(Suppl 1):i5-10. https://doi.org/10.1093/annonc/mdg702.

53. Dang NHOM, Castaigne S, Fayad LE, et al. Randomized, phase 3 trial of inotuzumab ozogamicin plus rituximab versus chemotherapy plus rituximab for relapsed/refractory aggressive B-cell non-Hodgkin lymphoma. Br J Haematol. 2018;182:579-609. https://doi.org/10.1111/bjh.14820.

54. Lee DW, Gardner R, Porter DL, et al. Current concepts in the diagnosis and management of cytokine release syndrome. Blood. 2014;124:188-95. https:// doi.org/10.1182/blood-2014-05-552729.

55. Porter D, Frey N, Wood PA, et al. Grading of cytokine release syndrome associated with the CAR T cell therapy tisagenlecleucel. J Hematol Oncol. 2018;11:35. https://doi.org/10.1186/s13045-0180571-y.

56. Lee DW, Santomasso BD, Locke FL, et al. ASTCT consensus grading for cytokine release syndrome and neurologic toxicity associated with immune effector cells. Biol Blood Marrow Transplant.
2019;25:625-38. https://doi.org/10.1016/j.bbmt. 2018.12.758.

57. Ionescu-Ittu R, Shang A, Velde NV, et al. Secondline rituximab-bendamustine versus rituximabgemcitabine-oxaliplatin in diffuse large B-cell lymphoma in the real world. J Comp Eff Res. 2019;8(13):1067-75. https://doi.org/10.2217/cer2019-0062.

58. Cheson BD, Fisher RI, Barrington SF, et al. Recommendations for initial evaluation, staging, and response assessment of Hodgkin and non-Hodgkin lymphoma: the Lugano classification. J Clin Oncol. 2014;32(27):3059-68. https://doi.org/10.1200/JCO. 2013.54.8800.

59. Cheson BD, Horning SJ, Coiffier B, et al. Report of an international workshop to standardize response criteria for non-Hodgkin's lymphomas. NCI Sponsored International Working Group. J Clin Oncol. 1999;17(4):1244. https://doi.org/10.1200/JCO. 1999.17.4.1244.

60. Cheson BD, Pfistner B, Juweid ME, et al. Revised response criteria for malignant lymphoma. J Clin Oncol. 2007;25(5):579-86. https://doi.org/10.1200/ JCO.2006.09.2403. 